\title{
Expression and Clinical Significance of miR-218 in Colorectal Cancer
}

\author{
Wen Jian $\mathrm{Xu}^{1}$, Wei Dong Song ${ }^{1}$, Song $\mathrm{Fei}^{2}$, Xiu Lan $\mathrm{Su}^{3}$ and Liu Ming ${ }^{2 *}$ \\ ${ }^{1}$ Department of General Surgery, Inner Mongolia Cancer Hospital, China \\ ${ }^{2}$ Department of General Surgery, Affiliated Hospital of Inner Mongolia Medical University, China \\ ${ }^{3}$ Clinical Research Centre, Affiliated Hospital of Inner Mongolia Medical University, China
}

Received: 眥: December 05, 2018; Published: 䙵: January 04, 2019

*Corresponding author: Liu Ming, Department of General Surgery, Affiliated Hospital of Inner Mongolia Medical University, Huhhot 100050, China

\begin{abstract}
Objective: To study expression levels of miR-218 in colorectal cancer and normal tissues.

Methods: Using real-time quantitative PCR to detect the expression levels of miR-218 in 60 cases of colorectal cancer and the corresponding normal tissues, calculate its relative expression.

Results: The relative expression of miR-218 in the tissues of 60 patients with colorectal cancer was $0.3297 \pm 0.2998$, which was significantly lower than the control group. The difference expression of miR-218 was statistically significant $(\mathrm{P}<0.05)$. There is no difference in the expressing of miR-218 in the gender, age, gross form, pathological type, differentiated degree, lymphatic metastasis, depth of invasion, UICC Stage(P>0.05). There are lower expressions in lymph node metastasis than in those without lymph node metastasis.

Conclusion: miR-218 showed low expression in colorectal cancer. Its lower expression levels may be prompted to lymph node metastasis sooner. MiR-218 may act as a tumor suppressor gene involved in tumor development.
\end{abstract}

Key words: Colorectal Cancer; miR-218; RT-PCR

\section{Introduction}

Colorectal cancer is one of the most common malignant tumors in the digestive tract, ranking 4 th in the fatal cause of malignant tumors [1], and its incidence is increasing year by year. Recurrence, metastasis and spread of tumors are still the main causes of death. Therefore, it is of great significance to further study the pathogenesis of colorectal cancer and find a more effective treatment for it. Studies have found that MicroRNAs (miRNAs or miRs) play an important role in cell proliferation, differentiation, apoptosis, gene regulation and tumor occurrence and development. Some miRNAs are involved in the mediation of tumor suppressor genes, while others play a role as oncogenes. Gene chip technology was used to detect the expression profile of miRNAs in various tumor tissue samples, and it was found that most miRNAs were down-regulated in tumor samples and a few miRNAs expression levels were up-regulated. More and more studies have shown that miRNAs have the role of oncogenes or tumor suppressors, and it plays an important role in the process of cell growth, proliferation and apoptosis. The abnormal expression level of miRNAs is related to the occurrence and development of many tumors. Therefore, the study of the relationship between miRNAs and tumor is of great significance for exploring the occurrence, development and treatment of tumors.

\section{Materials and Methods}

\section{General Information}

From June 2016 to June 2018, 60 fresh samples of colorectal cancer that were surgically excised and pathologically confirmed by the affiliated hospital of Inner Mongolia Medical University were collected as the experimental group and the corresponding normal tissue samples as the control group. No preoperative chemotherapy or radiation treatment was performed in all cases, and complete case data was available. 


\section{Experimental Methods}

Extraction and Detection of RNA: Tissue samples were taken within $1 \mathrm{~h}$ after excision, and quickly placed in a sterile enzymefree cryopreservation tube and stored in liquid nitrogen. Total RNA was extracted by TRIzol reagent. RNA concentration was measured using a DU800 nucleic acid protein analyser (BECKMAN, USA), and RNA integrity was detected by agarose gel electrophoresis.

Reverse Transcription: Complementary DNA first strand synthesis kit, miRcute miRNA fluorescence quantitative detection kit, miR-218 forward primer, reverse primer (provided by Beijing Tiangen Biochemical Technology Co., Ltd.), U6snRNA (provided by Zhongmeitaihe Co., Ltd.). U6 forward primer: 5'-CTCGCTTCGGCAGCACA-3'; U6 reverse primer: 5'-AACGCTTCACGAATTTGCGT-3'. Reaction system: $2 \mu \mathrm{g}$ total RNA; $2 \mu \mathrm{L}$ random primer; $2 \mu \mathrm{L}$ high purity dNTP; Make up RNase-Free ddH2O to $14.5 \mu \mathrm{L}$. After heating at $70{ }^{\circ} \mathrm{C}$ for $5 \mathrm{~min}$ and cooling for $2 \mathrm{~min}$, add the following line: $4 \mu \mathrm{L}$ of 5 -fold concentration of first strand synthesis buffer (containing DTT); $0.5 \mu \mathrm{L}$ of RNasin. Add $1 \mu \mathrm{L}(200 \mathrm{U})$ TIAN script M-MLV. Warm bath at $25^{\circ} \mathrm{C}$ for $10 \mathrm{~min}$; then warm bath at $42{ }^{\circ} \mathrm{C}$ for $50 \mathrm{~min}$. The reaction was terminated by heating at $95^{\circ} \mathrm{C}$ for $5 \mathrm{~min}$ and stored at $-20^{\circ} \mathrm{C}$.

PCR System and the Conditions: Add the following reaction system to a $0.2 \mathrm{~mL}$ octatube at $4{ }^{\circ} \mathrm{C}$ : $2 \times$ miRcute miRNA Premix 5 $\mu \mathrm{L} ; 50 \times$ ROX Reference Dye $0.8 \mu \mathrm{L}$; miR-218 forward primer $0.2 \mu \mathrm{L}$; reverse primer $0.2 \mu \mathrm{L}$; dd $\mathrm{H} 203.3 \mu \mathrm{l}$; complementary DNA $0.5 \mu \mathrm{L}$, total system $10 \mu \mathrm{L}$. PCR reaction conditions: $94^{\circ} \mathrm{C}$ for $2 \mathrm{~min}, 1$ cycle; $94^{\circ} \mathrm{C}$ for $20 \mathrm{~s}, 60^{\circ} \mathrm{C}$ for $34 \mathrm{~s}, 50$ cycles.

Detection of Relative Expression of miR-218: SYBR Green fluorescence quantitative PCR was used to detect the relative expression of miR-218 in colorectal cancer tissues and normal tissues using U6snRNA as an internal reference. The miR-218 expression level was calculated as RQ (relative expression amount) $=2-\Delta \Delta \mathrm{Ct} . \Delta \mathrm{Ct}=\mathrm{Ct}(\mathrm{miR}-218)-\mathrm{Ct}(\mathrm{U} 6) ; \Delta \Delta \mathrm{Ct}=\Delta \mathrm{Ct}$ (cancer tissue) $-\Delta \mathrm{Ct}$ (normal tissue). The higher the $\Delta \mathrm{Ct}$ value, the lower the expression of miR-218. In the real-time PCR technique, the Ct (CyC1ethreshold) value indicates the number of cycles experienced when the fluorescent signal in each reaction tube reaches a set domain value. There is a linear relationship between the Ct value of each template and the logarithm of the initial copy number of the template. The more the starting copy number, the smaller the $\mathrm{Ct}$ value.

\section{Statistical Method}

Statistical analysis was performed using SPSS 19.0. Measurement data were expressed as mean \pm standard deviation. Pairwise t-test and analysis of variance were used for comparison between groups. $\mathrm{P}<0.05$ was considered statistically significant.

\section{Results}

In this experiment, the amplification curve is concentrated, smooth, and has a stable plateau. The peak position is between 20 and 30 ct values (Figures 1 \& 2), indicating the amplification efficiency, specificity and template of the primers in this experiment. The amount is more appropriate. The dissolution curve is concentrated in a single peak (Figures $3 \& 4$ ), indicating that the specificity of the test is good, and the product is single. In 60 cancer patients, the relative expression of miR-218 in 2 cases was $>1,<1$ in 58 cases and $<0.5$ in 4 cases. Relative expression was $0.3297+$ 0.2998 . Cancer and normal tissue of miRNAs - 218 express multiple $2-\Delta \Delta \mathrm{Ct}$ difference $(\mathrm{t}=17.320, \mathrm{P}=0.000)$. The relative expression level of miR-218 was not significantly different among all factors except lymph node metastasis ( $\mathrm{P}>0.05)$, as shown in Table 1.

Table 1: Relationship between relative expression of miR-218 and clinicopathological features of patients.

\begin{tabular}{|c|c|c|c|c|c|}
\hline \multicolumn{6}{|c|}{ Relationship between Relative Expression of miR-218 and Clinicopathological Features of Patients } \\
\hline Characteristic & & Number $(n=100)$ & $2-\triangle \triangle \mathrm{Ct}(\bar{X} \pm \mathrm{S})$ & T or F & $\mathbf{P}$ \\
\hline \multirow{2}{*}{ Gender } & Male & 33 & $0.37 \pm 0.16$ & \multirow{2}{*}{1.35} & \multirow{2}{*}{0.26} \\
\hline & Female & 27 & $0.29 \pm 0.11$ & & \\
\hline \multirow{2}{*}{ Age } & $<65$ & 34 & $0.34 \pm 0.15$ & \multirow{2}{*}{0.28} & \multirow{2}{*}{1.14} \\
\hline & $\geq 65$ & 26 & $0.32 \pm 0.13$ & & \\
\hline \multirow{2}{*}{ Gross Form } & Uplift type & 31 & $0.35 \pm 0.09$ & \multirow{2}{*}{0.32} & \multirow{2}{*}{0.65} \\
\hline & Ulcer type & 29 & $0.31 \pm 0.12$ & & \\
\hline \multirow{2}{*}{ Pathological Type } & Adenocarcinoma & 56 & $0.32 \pm 0.14$ & \multirow{2}{*}{1.47} & \multirow{2}{*}{0.23} \\
\hline & Other Types of Cancer & 4 & $0.46 \pm 0.11$ & & \\
\hline \multirow{3}{*}{ Differentiated Degree } & Poor Differentiation & 4 & $0.39 \pm 0.18$ & \multirow{3}{*}{0.66} & \multirow{3}{*}{1.59} \\
\hline & Moderate Differentiation & 30 & $0.28 \pm 0.09$ & & \\
\hline & High Differentiation & 26 & $0.37 \pm 0.13$ & & \\
\hline \multirow{2}{*}{ Lymphatic Metastasis } & Yes & 15 & $0.28 \pm 0.11$ & \multirow{2}{*}{2.33} & \multirow{2}{*}{$0.02^{*}$} \\
\hline & No & 45 & $0.48 \pm 0.22$ & & \\
\hline \multirow{2}{*}{ The Depth of Invasion } & T1T2 & 10 & $0.30 \pm 0.17$ & \multirow{2}{*}{0.57} & \multirow{2}{*}{0.64} \\
\hline & T3T4 & 50 & $0.34 \pm 0.10$ & & \\
\hline \multirow{3}{*}{ UICC Stage } & I & 8 & $0.27 \pm 0.12$ & \multirow{3}{*}{2.87} & \multirow{3}{*}{0.08} \\
\hline & II & 36 & $0.28 \pm 0.12$ & & \\
\hline & III & 16 & $0.47 \pm 0.21$ & & \\
\hline
\end{tabular}

Cite this article: Wen Jian Xu, Wei Dong Song, Song Fei, Xiu Lan Su, Liu Ming. Expression and Clinical Significance of miR-218 in Colorectal 


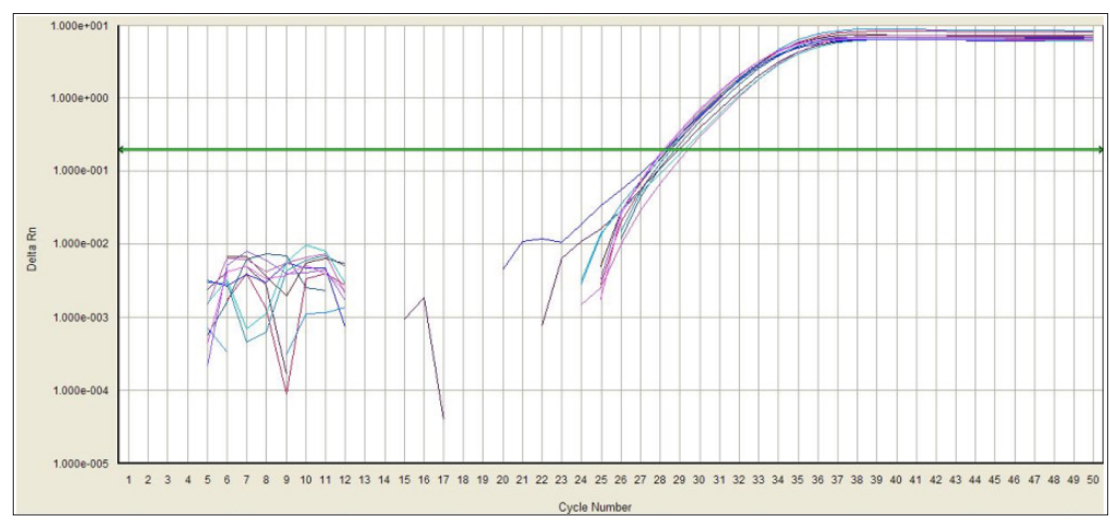

Figure 1: Amplification curve of miR-218.

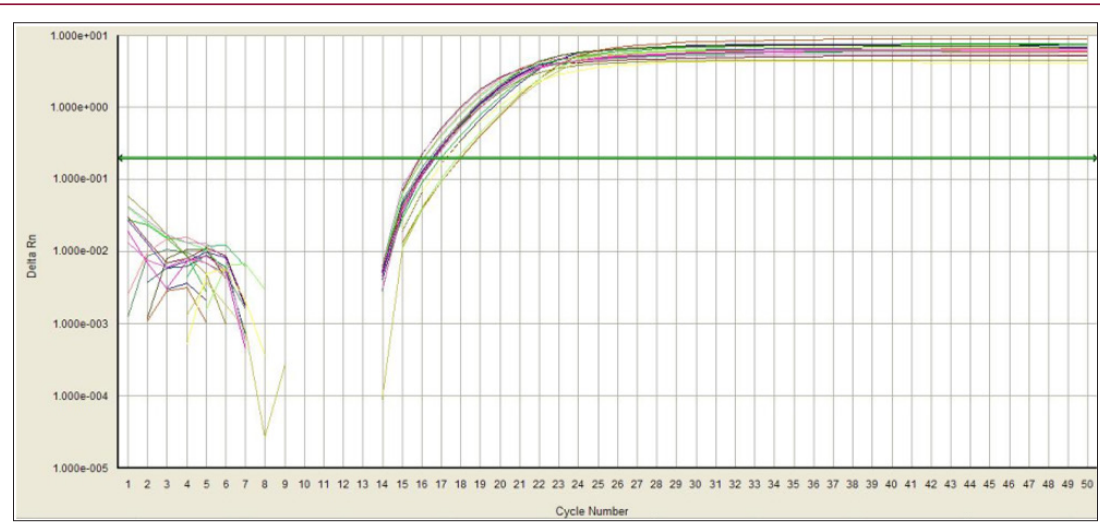

Figure 2: Amplification curve of U6.

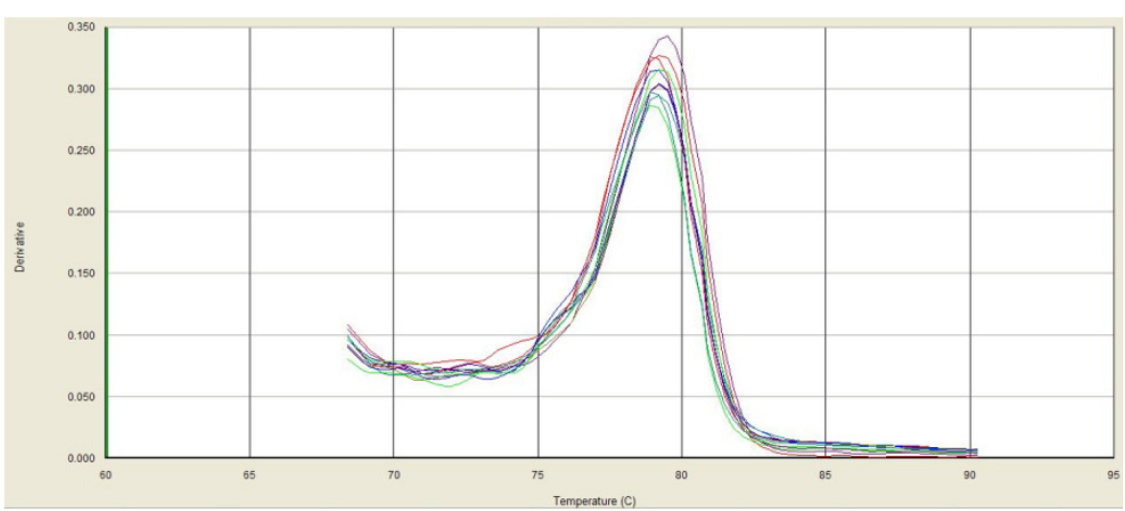

Figure 3: Dissolution curve of miR-218.

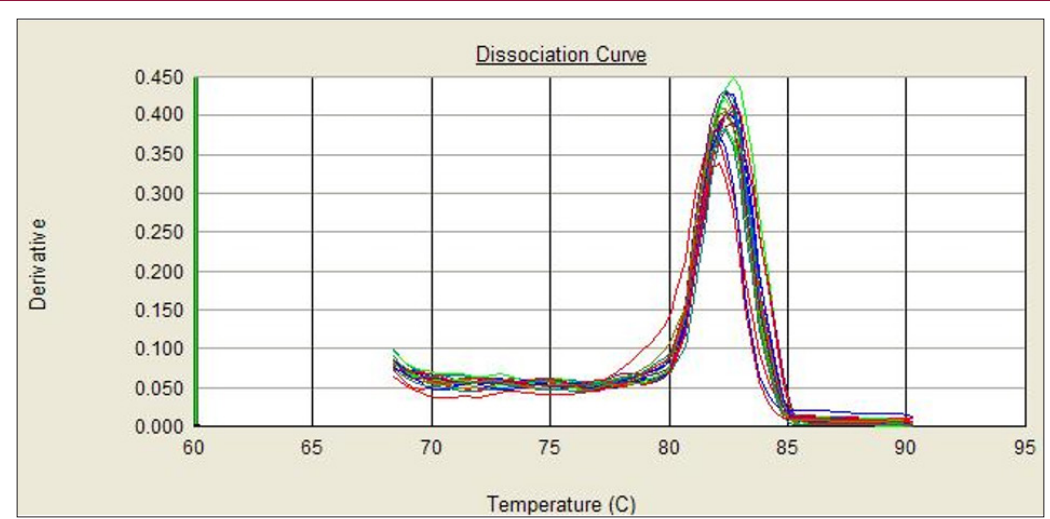

Figure 4: Dissolution curve of U6. 


\section{Discussion}

By analysing more patients with colorectal cancer, miR218 expression was significantly decreased in colorectal cancer compared to non-tumor tissues. Low expression of miR-218 was also demonstrated in comparison of colon cancer cell lines with normal colon tissue [2]. The down-regulation of miR-218 also appeared in other cancers, including gastric cancer [3-4], glioma [5], nasopharyngeal cancer [6], lung cancer [7] and bladder cancer [8]. Human miR-218 contains two different genes (miR-218-1 and miR-218-2), which are processed to encode an identical mature sequence. MiR-218-1 and miR-218-2 were embedded in the introns of SLIT2 gene on chromosome 4p15.2 and SLIT3 gene on chromosome 5q35.1, respectively. 4p15.1 15.3 frequent absences can lead to colorectal cancer [9]. Therefore, heterozygous deletions in this region may be associated with down regulation of miR218 in colorectal cancer patients. On the other hand, SLIT family host genes are often inactivated in colorectal cancer through their promoter methylation [10]. Studies have found that the expression of miR-218 restores when the DNA methylation inhibitor 5-aza2 '-deoxycytidine is used in colorectal cancer cell lines. In nasopharyngeal carcinoma and oral squamous cell carcinoma, miR218 is down regulated by promoter methylation [11-12].

These data suggest that methylation of the CpG island (the dinucleotide genome segment) may also contribute to miR-218 silencing in colorectal cancer. In the tumor origin stage of colorectal cancer, down regulated miR-218 means that it may play a role as a potential tumor suppressor gene. The experimental results show that miR-218 expression in colorectal cancer tissue level is significantly lower than that of normal tissue. MiR-218 May play the role of tumor suppressor gene in colorectal cancer and improve the level of the expression of miR-218 may be a potential for colorectal cancer treatments. From the level of expression of miR-218 and the relationship between the clinicopathological features of colorectal cancer can be seen that, miR-218 expression level and gender, age, clinical stage, tumor gross morphology, histology, has nothing to do with infiltrating depth and differentiation degree of tumor, associated with lymph node metastasis, The expression was lower in those with lymph node metastasis than in those without (the data in the Table 1 has been adjusted). The lower the expression level of miR-218 in colorectal cancer may indicate the earlier lymph node metastasis, and miR-218 may be involved in the occurrence and development of tumor as a tumor suppressor gene and is expected to be a molecular marker for the diagnosis and prognosis of colorectal cancer [13].

\section{References}

1. Yang L, Parkin DM, Li L, Chen Y (2003) Time trends in cancer mortality in China: 1987-1999. Int J Cancer 106(5): 771-783.

2. He X, Dong Y, Wu CW, Zengren Zhao, Simon S M Ng, et al. (2012) MicroRNA-218 inhibits cell cycle progression and promotes apoptosis in colon cancer by downregulating BMI1 polycomb ring finger oncogene. Mol Med 18(1): 1491-1498.

3. Gao C, Zhang Z, Liu W, Xiao S, Gu W, et al. (2010) Reduced microRNA-218 expression is associated with high nuclear factor kappa B activation in gastric cancer. Cancer 116(1): 41-49.

4. Song L, Huang Q, Chen K, Liu L, Lin C, et al. (2010) miR-218inhibits the invasive ability of glioma cells by direct downregulation of IKK- $\beta$. Biochem Biophys Res Commun 402(1): 135-140.

5. Gao Y, Sun L, Wu Z, Chengmin Xuan, Junxia Zhang, et al. (2018) miRNAs-218 inhibits the proliferation of human glioma cells through downregulation of Yin Yang 1. Mol Med Rep 17(1): 1926-1932.

6. Alajez NM, Lenarduzzi M, Ito E, Hui AB, Shi W, et al. (2011) miR-218 suppresses nasopharyngeal cancerprogression through downregulation of survivin and the SLIT2-ROBO1 pathway. Cancer Res 71(6): 23812391.

7. Wu DW, Chuang CY, Lin WL, Sung WW, Cheng YW, et al. (2014) Paxillin promotes tumorprogression and predicts survival and relapse in oral cavity squamous cellcarcinoma by microRNA-218 targeting[J]. Carcinogenesis 35(8): 1823-1829.

8. Tatarano S, Chiyomaru T, Kawakami K, Enokida H, Yoshino H, et al. (2011) miR-218 on the genomic lossregion of chromosome 4p15.31 functions as a tumor suppressor in bladder cancer. Int J Oncol 39(1): 13-21.

9. Shivapurkar N, Maitra A, Milchgrub S, Adi F Gazdar (2001) Deletions of chromosome 4 occur early during the pathogenesis of colorectal carcinoma. Hum Pathol 32(2): 169-177.

10. Dallol A, Morton D, Maher ER, Latif F (2003) SLIT2 axon guidance molecule isfrequently inactivated in colorectal cancer and suppresses growth of colorectalcarcinoma cells. Cancer Res 63(5): 1054-1058.

11. Alajez NM, Lenarduzzi M, Ito E, Hui AB, Shi W, et al. (2011) miR-218 suppresses nasopharyngeal cancerprogression through downregulation of survivin and the SLIT2-ROBO1 pathway. Cancer Res 71(6): 23812391.

12. Uesugi A, Kozaki K, Tsuruta T, Furuta M, Morita K, et al. (2011) The tumor suppressive microRNA miR-218 targets the mTOR component Rictor andinhibits AKT phosphorylation in oral cancer. Cancer Res 71(17): 5765-5778.

13. Meng Q, Chen Y, Lian B, Shang Y, Yang H (2018) miRNAs-218 promotes apoptosis of SW1417 human colon cancer cells by targeting c-FLIP. Oncol Rep 40(2): 916-922.

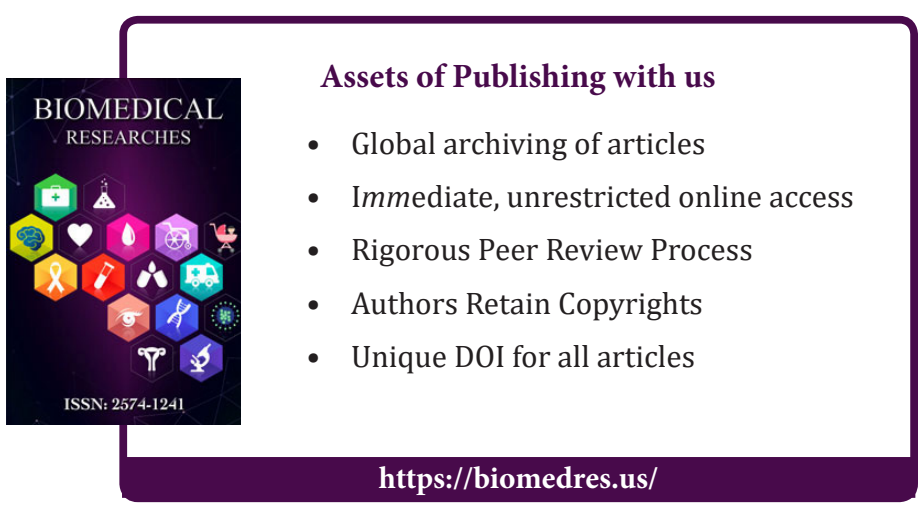

https://biomedres.us/

\section{ISSN: 2574-1241}

DOI: 10.26717/BJSTR.2019.12.002307

Liu Ming. Biomed J Sci \& Tech Res

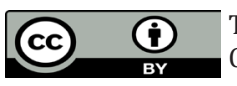

This work is licensed under Creative Commons Attribution 4.0 License

Submission Link: https://biomedres.us/submit-manuscript.php 